\title{
Comparison of opioid rotation on pain, symptoms, and daily opioid dose in a supportive care clinic
}

\author{
Luke P. Legakis $^{1,2} \wedge$, Wendy Woo ${ }^{1}$, J. Brian Cassel $^{1}$, Egidio Del Fabbro ${ }^{1 \wedge}$ \\ ${ }^{1}$ Massey Cancer Center, Virginia Commonwealth University, Richmond, VA, USA; ${ }^{2}$ Department of Internal Medicine, Yale School of Medicine, \\ New Haven, CT, USA \\ Contributions: (I) Conception and design: LP Legakis, JB Cassel, E Del Fabbro; (II) Administrative support: JB Cassel, E Del Fabbro; (III) Provision \\ of study materials or patients: JB Cassel, E Del Fabbro; (IV) Collection and assembly of data: All authors; (V) Data analysis and interpretation: All \\ authors; (VI) Manuscript writing: All authors; (VII) Final approval of manuscript: All authors. \\ Correspondence to: Luke P. Legakis. 333 Cedar St, New Haven, CT 06510, USA. Email: luke.legakis@yale.edu.
}

\begin{abstract}
Backgroundk Opioid rotation (OR) is used to decrease patients' cancer-related pain and mitigate opioidinduced adverse effects. There is limited evidence regarding its effect on symptoms and morphine equivalent daily dose (MEDD). The objective of this study was to investigate the effects of OR on pain scores, Edmonton Symptom Assessment Score (ESAS), and MEDD in patients with cancer.

Methods: Retrospective observational study in an outpatient supportive care clinic using a within-subject design to analyze data collected over 34 months. Study included 676 patients with 217 rotations identified in 128 patients at supportive care clinic at a National Cancer Institute (NCI) Cancer Center. OR were identified and analysis compared the pre-visit data with the subsequent post-visit data following OR using paired $t$-tests. Primary endpoints included pain scores, total ESAS, and MEDD for OR and these endpoints were compared amongst rotations to specific opioid analgesics.
\end{abstract}

Results: Following OR, there was a statistically significant reduction in mean pain scores from 6.25 at the pre-visit to 5.75 following OR. Of the 194 ORs, $29.90 \%$ were successful in reducing patients' pain by either $30 \%$ or by 2 -points. Only rotations to morphine, oxycodone, and methadone correlated with significant decreases in pain scores. Overall, OR did not correlate with significant changes in ESAS or MEDD. Only rotations to methadone correlated with a significant reduction in MEDD.

Conclusions: These findings suggest OR is associated with decreased pain scores without increasing MEDD. Of the agents compared, only rotations to methadone correlated with both a significant reduction in pain scores and in MEDD.

Keywords: Pain; opioid rotation (OR); morphine equivalent daily dose (MEDD); Edmonton Symptom Assessment Score (ESAS)

Submitted Feb 05, 2021. Accepted for publication May 10, 2021.

doi: 10.21037/apm-21-325

View this article at: http://dx.doi.org/10.21037/apm-21-325

\section{Introduction}

Pain is the primary reason for referral to outpatient palliative care (1) and opioid agonists remain the preferred treatment for cancer-related pain (2,3). A Cochrane review found 19 out of 20 people with moderate or severe pain able to tolerate opioids, experienced reduced pain within 14 days (4). Pain control in the palliative care setting can be complicated by many factors including progression of disease (5), analgesic tolerance (6), non-medical opioid use (NMOU) (7-9), and side effects such as sedation and delirium (10). These side effects, along with severe pain

\footnotetext{
^ ORCID of Luke P. Legakis: 0000-0001-9279-1142; Egidio Del Fabbro: 0000-0003-1245-6307.
} 
$(11,12)$ are major clinical challenges that may be mitigated by opioid rotation (OR), where one opioid is switched for another.

There is a growing body of literature documenting the effects of OR on pain and other patient-related outcomes as well as equianalgesic dosing conversions to help determine an appropriate dose once an agent is selected (13-15). However, a systematic review from the European Palliative Care Research Collaborative reported that 'firm evidence' for the benefits of opioid switching is still missing, and there is limited evidence comparing ORs to help guide clinical decision-making (16).

While several studies have determined equianalgesic ratios and effects of OR on pain, symptoms assessments, and morphine equivalent daily dose (MEDD) $(11,14,17)$, there is limited data comparing OR across several specific opioids that utilize subjective but quantitative outcomes such as pain scores and symptom assessment tools. The objective of the present retrospective study was to investigate the associations of OR overall on pain scores, total Edmonton Symptom Assessment Scores (ESAS), and MEDD in a cohort of palliative care patients. A secondary objective was to compare rotations from a different opioid to the following agents: morphine, oxycodone, methadone, hydromorphone, fentanyl, and hydrocodone. We present the following article in accordance with the STROBE reporting checklist (available at http://dx.doi.org/10.21037/ apm-21-325).

\section{Methods}

An observational retrospective chart review of 676 supportive care clinic patients seen at a National Cancer Institute (NCI) cancer center from August 2012 to June 2015 across 3,373 supportive care visits. Patients, ages 18 years or older with at least two consecutive visits were included $(\mathrm{n}=456)$. Patients were included for analysis if they underwent an OR: operationally defined as a change in a patient's opioid analgesic pain regimen from at least one opioid to a different opioid without the addition or subtraction of any other opioid analgesics $(n=128)$. Demographic data was also analyzed for patients that did not undergo an OR $(\mathrm{n}=328)$. The study was conducted in accordance with the Declaration of Helsinki (as revised in 2013). The study was approved by the IRB at Virginia Commonwealth University (HM14594) and individual consent for this retrospective analysis was waived.

A total frequency of rotations $(n=217)$ was analyzed as some patients underwent more than one OR during the timeframe that this data was collected. The "pre-visit" was defined as the first of two subsequential visits and the "post-visit" was the second of two subsequential visits. The average time between all pre-visits and post-visits was 34.47 days. Data collected from subsequent visits where a rotation did not occur were also included for comparison $(n=2,099)$. If data from either the pre-visit or post-visit were not available with regards to pain scores, ESAS, or MEDD, it was not included for analysis.

\section{Patient-related endpoints}

Patient characteristics included age, sex, and race/ethnicity per electronic medical record (EMR) review. For patients that underwent an OR, rotations were analyzed with data collected from the pre-visit at which point the patient's endpoints were assessed and compared to their consecutive subsequent visit, or post-visit. The primary endpoint for this observational retrospective study was reported pain scores for both the pre-visits and post- visits. A "successful" visit was operationally defined as a $30 \%$ or 2 -point reduction in pain scores at the post-visit (11). Additional criteria such as reduced side effects, lack of worsening of pain score with change of route of administration, and continued use of new opioid at subsequent visit were not included in the definition of "successful" rotation for this study due to unavailability of this data. An "adverse" visit was defined as a $30 \%$ or 2 -point increase in pain scores at the post-visit. Similar data was compared for subsequent visits in which a rotation did not occur.

Further endpoints analyzed in this study compared post-visit symptom scores following an OR with pre-visit symptom scores. The Edmonton Symptom Assessment System (ESAS) scores were analyzed in this study. The total ESAS has been used in the palliative care clinical setting and in research, with higher scores indicating greater symptom burden (18). Morphine Equivalent Daily Dosages (MEDD) were also compared. MEDD calculations standardize dosing across the various opioid analgesic agents to compare total opioid dose with morphine as the standard (19). MEDDs were calculated using parameters previously described over 24 hours: morphine doses were multiplied by a factor of 1 , oxycodone doses were multiplied by a factor of 1.5 , methadone doses by a factor of 5, hydromorphone doses by a factor of 4 , fentanyl transdermal doses ( $\mu \mathrm{g} / \mathrm{hour}$ ) by 2.4 and used as ( $\mathrm{mg} /$ day), and hydrocodone doses by a factor of $1.5(14,17)$. Doses included in the analysis were determined 
Table 1 Patient characteristics

\begin{tabular}{|c|c|c|}
\hline Patient characteristics & Patients with an opioid rotation ( $n=128), n(\%)$ & Patients without an opioid rotation $(n=328), n(\%)$ \\
\hline $18-39$ & $19(14.84)$ & $31(9.45)$ \\
\hline $40-59$ & $78(60.94)$ & $173(52.74)$ \\
\hline $60-79$ & $29(22.65)$ & $114(34.76)$ \\
\hline \multicolumn{3}{|l|}{ Sex } \\
\hline Female & $68(53.13)$ & $161(49.09)$ \\
\hline Male & $60(46.88)$ & $167(50.91)$ \\
\hline \multicolumn{3}{|l|}{ Race/ethnicity } \\
\hline Caucasian & $79(61.72)$ & $179(54.57)$ \\
\hline Hispanic & $3(2.34)$ & $0(0.00)$ \\
\hline Other/unknown & $0(0.00)$ & $9(2.74)$ \\
\hline
\end{tabular}

by prescriptions in the EMR at the time of the visits and included the full PRN or "as needed" doses available within a 24-hour period.

Analysis was also performed to describe the effects of rotating to particular opioid analgesics. Data is expressed for ORs as a whole, as the specific opioid rotated to, and as visits without an OR. For clarity, the drug rotated to would be the opioid analgesic the patient was on between the pre-visit and post-visit with an active prescription at the date of the post-visit. An OR to one opioid did not exclude its analysis if an additional OR occurred during the same visit. If a visit resulted in multiple ORs, it was counted as one total OR but could be reflected in multiple specific drug ORs.

\section{Statistical analysis}

All patient characteristic measures were summarized using frequencies, percentages, and means in Table 1. Pain scores, total ESAS scores and MEDDs are expressed with mean and $95 \%$ confidence intervals in Tables 2-4. Data analysis of ORs compared the endpoints (pain scores, total ESAS scores, and MEDDs) using a within-subject paired $t$-test with $\mathrm{P}$ values reported. Statistical significance was determined by $\mathrm{P}$ value less than 0.05 (alpha). Statistical analysis and descriptive data results were performed using
Prism 8.0 (Graphpad Software Inc., San Diego, CA).

\section{Results}

Of the 676 patients seen across 3,373 supportive care visits, 128 patients underwent an OR, 328 did not undergo OR, and 220 had only one visit. Table 1 outlines the patient characteristics for those that underwent an OR and those who did not. There were no differences in demographic data. The interval of time between visits in which an OR occurred was significantly shorter with a mean of 29.55 days compared to mean interval period of 35.32 days for visits in which OR did not occur $(\mathrm{P}=0.03)$.

Table 2 shows the effect of OR on mean pain scores. There was a statistically significant reduction in mean pain scores from 6.25 at the pre-visit to $5.75(\mathrm{P}=0.001)$ at the post-visit following OR with $29.90 \% \quad(n=194)$ considered as "successful" visits (see methods section) compared to $24.49 \%$ "successful" visits without an OR $(\mathrm{n}=1,866)$; $13.92 \%$ of visits that included an OR were considered "adverse" visits (see methods) compared to $18.65 \%$ without an OR. The baseline mean pain scores for visits in which an OR occurred were significantly higher than those without an OR. Rotations to morphine, oxycodone, and methadone all correlated with significant decreases in overall pain scores at the post-visit following OR while rotations to 
Table 2 Association of opioid rotation and pain scores

\begin{tabular}{|c|c|c|c|c|c|c|}
\hline Drug rotated to & $\begin{array}{l}\text { Number of } \\
\text { rotations }\end{array}$ & \multicolumn{3}{|c|}{ Pain score $(0$ to 10$)$, mean $(95 \% \mathrm{Cl})$} & $\begin{array}{l}\text { Percent successful } \\
\text { rotation (\%) }\end{array}$ & $\begin{array}{c}\text { Percent adverse } \\
\text { rotation (\%) }\end{array}$ \\
\hline Morphine & 64 & $6.59(5.97,7.22)$ & $6.03(5.39,6.69)$ & $0.017^{*}$ & 25.00 & 9.38 \\
\hline Oxycodone & 43 & $5.88(5.20,6.57)$ & $5.35(4.66,6.04)$ & $0.040^{*}$ & 34.88 & 9.30 \\
\hline Methadone & 43 & $6.51(5.78,7.24)$ & $5.63(4.87,6.39)$ & $0.024^{*}$ & 34.88 & 9.30 \\
\hline Fentanyl & 24 & $6.33(5.37,7.30)$ & $5.71(4.58,6.84)$ & 0.174 & 25.93 & 8.33 \\
\hline Hydrocodone & 6 & $5.50(1.94,9.06)$ & $5.50(4.22,6.79)$ & $>0.999$ & 33.33 & 50.00 \\
\hline Total OR visits & 194 & $6.25(5.93,6.57)$ & $5.75(5.42,6.09)$ & $0.001^{*}$ & 29.90 & 13.92 \\
\hline Visits without an OR & 1,866 & $5.24(5.12,5.37)$ & $5.38(5.13,5.64)$ & 0.259 & 24.49 & 18.65 \\
\hline
\end{tabular}

*, $\mathrm{P}<0.05$. Pain scores are displayed as mean with $95 \% \mathrm{Cl}$ (upper limit, lower limit).

Table 3 Association of opioid rotation and ESAS

\begin{tabular}{|c|c|c|c|c|}
\hline \multirow{2}{*}{ Drug rotated to } & \multirow{2}{*}{$\begin{array}{c}\text { Number of } \\
\text { rotations }\end{array}$} & \multicolumn{3}{|c|}{ ESAS } \\
\hline & & Pre-visit & Post-visit & $P$ value \\
\hline Morphine & 52 & $45.40(40.69,50.12)$ & $43.87(38.98,48.75)$ & 0.464 \\
\hline Oxycodone & 34 & $39.76(34.09,45.44)$ & $37.24(30.41,44.06)$ & 0.364 \\
\hline Methadone & 31 & $42.45(36.22,48.68)$ & $36.97(31.81,42.13)$ & 0.089 \\
\hline Fentanyl & 22 & $38.77(29.86,47.69)$ & $41.68(33.74,49.63)$ & 0.323 \\
\hline Hydrocodone & 6 & 27.33 (11.01 43.65) & $30(17.23,42.77)$ & 0.511 \\
\hline Total OR visits & 155 & $40.74(38.01,43.48)$ & $39.10(36.42,41.78)$ & 0.172 \\
\hline Visits without an OR & 1,608 & $34.01(33.10,34.92)$ & $34.54(33.19,35.89)$ & 0.394 \\
\hline
\end{tabular}

ESAS scores are displayed as mean with $95 \% \mathrm{Cl}$ (upper limit, lower limit). ESAS, Edmonton symptom assessment score.

Table 4 Association of opioid rotation and MEDD

\begin{tabular}{|c|c|c|c|c|}
\hline Drug rotated to & $\begin{array}{c}\text { Number of } \\
\text { rotations }\end{array}$ & \multicolumn{3}{|c|}{ MEDD (mg/day) } \\
\hline Morphine & 70 & $387.43(260.77,514.08)$ & $385.47(270.91,500.03)$ & 0.949 \\
\hline Oxycodone & 48 & $382.21(257.38,507.04)$ & $404.24(280.66,527.82)$ & 0.626 \\
\hline Methadone & 48 & $407.90(279.60,536.30)$ & $277.20(201.40,353.00)$ & $0.003^{*}$ \\
\hline Fentanyl & 23 & $433.86(292.37,575.34)$ & $405.50(268.88,542.12)$ & 0.383 \\
\hline Hydrocodone & 6 & $154.22(5.25,303.19)$ & $155.56(4.15,306.96)$ & 0.949 \\
\hline Total OR visits & 217 & $402.38(338.76,466.01)$ & $391.34(329.63,453.05)$ & 0.541 \\
\hline Visits without an OR & 2,099 & $279.13(262.73,295.53)$ & $276.41(260.17,292.64)$ & 0.375 \\
\hline
\end{tabular}

*, $\mathrm{P}<0.05$. MEDD are displayed as mean with $95 \% \mathrm{Cl}$ (upper limit, lower limit) in mg/day. MEDD, morphine equivalent daily dose. 
hydromorphone, fentanyl, and hydrocodone did not correlate with a significant change in overall pain scores.

Table 3 describes the effect of OR on mean ESAS scores. OR did not correlate with significant changes in ESAS scores with the pre-visit mean of 40.74 and the post-visit mean of 39.10. Visits without an OR did not correlate with any changes in ESAS scores with pre-visit mean of 34.01 and post-visit mean of 34.54. Additionally, no OR to a particular agent significantly affected total ESAS scores, with methadone producing a statistically nonsignificant decrease from 42.45 to 36.97 . Further subanalysis demonstrated no significant change with any of the individual symptoms captured within the ESAS questions following OR (data not shown). The baseline total ESAS of visits in which an OR occurred were significantly higher than those without an OR.

Table 4 describes the change in MEDD with OR. There was no significant change in MEDD with OR. The overall MEDD was statistically unchanged with $402.38 \mathrm{mg}$ /day at the pre-visit and $391.34 \mathrm{mg} /$ day at the post-visit following OR. OR to methadone were the only rotations that showed a statistically significant decrease in mean MEDD from $406.41 \mathrm{mg} /$ day to $279.62 \mathrm{mg} /$ day $(\mathrm{P}=0.004)$. There were no differences in MEDD in visits without a rotation with previsit mean of $279.13 \mathrm{mg} /$ day compared to $276.41 \mathrm{mg} /$ day. The baseline MEDD of visits in which an OR occurred were significantly higher than those where an OR did not occur.

\section{Discussion}

This retrospective study investigated the effects of ORs in a cohort of patients seen in the outpatient palliative care setting. There were four main findings. First, ORs overall correlated with statistically significant decreases in pain scores, with almost one-third of rotations decreasing scores by either 2 points or $30 \%$. Second, ORs did not correlate with any overall changes to the total symptom assessment profile (ESAS) or to the MEDD. Third, ORs to morphine, oxycodone, and methadone demonstrated statistically significant decreases in mean pain scores while ORs to hydromorphone, fentanyl, and hydrocodone did not. Fourth, only ORs to methadone correlated in a significant decrease in standardized dosing, MEDD. Our findings regarding methadone are consistent with a recent systematic review reporting increased MEDD following OR, with only rotation to methadone correlating in a decreased MEDD (20) and with a study that demonstrated enhanced reduction in pain scores with OR to methadone compared to other ORs (21). Moreover, our findings suggest that OR can be effective at reducing patient's reported pain scores without increasing MEDD. We did not find any improvements associated with OR on the additional symptoms captured in the ESAS. However, the ESAS questionnaire does not include assessment of other opioid side effects such as constipation, delirium, and overall tolerability.

While this study contributes to the body of evidence suggesting improved pain symptoms following an opioid OR using a within-subject design $(20,22,23)$, the mechanisms for this benefit is poorly understood (24). A current theory revolves around receptor polymorphisms and that each opioid agent has a distinct mu-opioid signature (25-29).

Of the possible agents a clinician can rotate to, methadone is considered unique in terms of its pharmacodynamics and pharmacokinetics. Methadone has agonist activity at both the mu-opioid receptors and antagonist activity at the N-methyl-D-aspartate (NMDA) receptors with contributions of both effects demonstrating contribution to analgesia $(30,31)$. Methadone also has favorable pharmacokinetics with a half-life of 24 hours (in non-opioid naïve individuals) that typically requires only twice a day dosing which is favorable to patients (32) while some benefit from every 8 -hour dosing. There are several other benefits of utilizing methadone in palliative medicine including its safety profile in renal failure (33), cost (34), and efficacy in neuropathic pain (35).

While OR has demonstrated benefit in terms of opioidrelated side effects $(36,37)$, this study was not designed to investigate the full profile of opioid-related adverse effects, as the data available was limited in this regard. The nonsignificant results with ESAS scores do not exclude the possibility of benefit regarding constipation, neurotoxicity, sedation, or overall tolerability which are frequent reasons for OR. The finding that the baseline total ESAS was significantly higher in visits in which an OR occurred would suggest that symptom burden likely was a component in the decision to perform an OR. These results are consistent with prior reports that decreases in overall symptom burden assessed with ESAS scores are not universally present following OR $(15,38)$.

ORs in this cohort of palliative care patient did not correlate with changes to the MEDD. This may largely be attributed to the primary purpose of an OR in the outpatient clinic: improving pain management and mitigating the risk of adverse effects. However, prescriptions in this cohort of 
patients did not result in decreases MEDD that are often encouraged with OR (39). In addition, visits that included an OR had higher pain scores and MEDDs than those without OR. While information regarding reasons for rotation in this study was not available, this result suggests that patients are either requiring higher doses to achieve pain relief or may be prone to increased opioid-related adverse effects secondary to dosage (40).

Methadone was the only exception, demonstrating an overall decrease in MEDD. There are several reasons for this result. It is possible the unique characteristics of methadone provide pain relief at lower equianalgesic doses $(41,42)$. Perhaps the true MEDD of methadone is underestimated; this is supported by a recent observational study suggesting the equianalgesic ratio may be closer to 10:1 (43). In addition, the conversion ratios for methadone are not standardized, and variable. Conversion ratios of morphine to methadone are non-linear; they vary with dose and the reasons for rotation (side effects are 9:1 vs. 5:1 for uncontrolled pain) (44). In our population of ambulatory clinic patients, inadequate pain control prior to rotation is a more likely reason for rotation than side effects such as sedation. Evidence for conversion ratios from methadone to morphine are even more limited and may not vary with increasing dose (42). The final reason may be attributed to concerns by clinicians or patients regarding the adverse effects of methadone such as QT prolongation (45), the stigma surrounding its use for opioid use disorder (46), or a combination of the two with prescribers writing for artificially lower doses of methadone than the other opioid analgesics.

This study has several limitations. Since this is a retrospective study, only correlations regarding endpoints could be determined, and the data was limited in some cases. Due to the lack of availability of information regarding full profile of opioid-induced side effects, continuation of rotated opioids, disease progression, and reason for rotation, this study chose to focus the primary endpoint as mean pain scores and as the sole indicator of a successful OR. As a consequence, it is likely the data presented underestimates what many would consider a "successful" OR (11). Our study size limits a full comparison of drug effects, as only within-subject analyses were performed. We also based the MEDD on the clinician's prescribed dose, because pill-counts were not consistently performed. Patients may actually be taking medications (particularly as needed or PRN) less frequently than prescribed. This study was also limited in that only one subsequent visit was included for analysis and it is unknown to what extent these results are sustained over longer intervals of time. Additional prospective studies and larger retrospective studies are needed to validate the findings of this study and to further compare the ORs to particular agents.

While this study demonstrated statistically significant reductions in mean pain scores following OR, the effect was relatively small with less than a one-point reduction in mean pain scores. In addition, while OR visits resulted in increased "successful" visits and decreased "adverse" visits determined by pain scores compared visits without an $\mathrm{OR}$, the clinical significance of this improvement remains unclear as supportive care visits alone appeared to be relatively successful in reducing pain scores with over $20 \%$ of all visits resulting in decreased pain scores. Overall, OR correlated with a minimal, but significant, reduction in mean pain scores without increasing MEDD despite having higher baseline pain scores, symptom burden, and current opioid dosing compared to visits without OR, supporting the utility of OR in patients who may benefit.

\section{Conclusions}

OR correlated with improved pain scores without an increase in standardized dosing. A comparison of opioid analgesic agents revealed rotations to methadone had the most favorable profile with significant decreases in pain scores in the setting of decreased MEDD.

\section{Acknowledgments}

Services and products in support of the research project were generated by the Virginia Commonwealth University Massey Cancer Center Cancer Informatics Core.

Funding: This work was funded by the National Institute of Health (P30 CA016059, F30 CA213956, 1R01CA22570101A1, 1R01AG061558-01A1).

\section{Footnote}

Reporting Checklist: The authors have completed the STROBE reporting checklist. Available at http://dx.doi. org/10.21037/apm-21-325

Data Sharing Statement: Available at http://dx.doi. org/10.21037/apm-21-325

Peer Review File: Available at http://dx.doi.org/10.21037/ 
apm-21-325

Conflicts of Interest: All authors have completed the ICMJE uniform disclosure form (available at http://dx.doi. org/10.21037/apm-21-325). Dr. EDF serves as an unpaid editorial board member of Annals of Palliative Medicine from Mar 2019 to Feb 2021. Dr. EDF reports consulting fees from Pfizer. The other authors have no conflicts of interest to declare.

Ethical Statement: The authors are accountable for all aspects of the work in ensuring that questions related to the accuracy or integrity of any part of the work are appropriately investigated and resolved. The study was conducted in accordance with the Declaration of Helsinki (as revised in 2013). The study was approved by the IRB at Virginia Commonwealth University (HM14594) and individual consent for this retrospective analysis was waived.

Open Access Statement: This is an Open Access article distributed in accordance with the Creative Commons Attribution-NonCommercial-NoDerivs 4.0 International License (CC BY-NC-ND 4.0), which permits the noncommercial replication and distribution of the article with the strict proviso that no changes or edits are made and the original work is properly cited (including links to both the formal publication through the relevant DOI and the license). See: https://creativecommons.org/licenses/by-nc-nd/4.0/.

\section{References}

1. Alam S, Pope A, Le L, et al. Outpatient palliative medicine consultations: urgent or routine? BMJ Support Palliat Care 2021;11:149-55.

2. Scarborough BM, Smith CB. Optimal pain management for patients with cancer in the modern era. CA Cancer J Clin 2018;68:182-96.

3. Steins MB, Eschbach C, Villalobos M, et al. Pain Management in Palliative Care. Pneumologie 2017;71:297-306

4. Wiffen PJ, Wee B, Derry S, et al. Opioids for cancer pain an overview of Cochrane reviews. Cochrane Database Syst Rev 2017;7:CD012592.

5. Bischoff K, Weinberg V, Rabow MW. Palliative and oncologic co-management: symptom management for outpatients with cancer. Support Care Cancer 2013;21:3031-7.

6. Vella-Brincat J, Macleod AD. Adverse effects of opioids on the central nervous systems of palliative care patients. J Pain Palliat Care Pharmacother 2007;21:15-25.

7. Pinkerton R, Hardy JR. Opioid addiction and misuse in adult and adolescent patients with cancer. Intern Med J 2017;47:632-6.

8. Bruera E, Del Fabbro E. Pain Management in the Era of the Opioid Crisis. Am Soc Clin Oncol Educ Book 2018;38:807-12.

9. Rauenzahn S, Sima A, Cassel B, et al. Urine drug screen findings among ambulatory oncology patients in a supportive care clinic. Support Care Cancer 2017;25:1859-64.

10. Benyamin R, Trescot AM, Datta S, et al. Opioid complications and side effects. Pain Physician 2008;11:S105-20.

11. Reddy A, Yennurajalingam S, Pulivarthi K, et al. Frequency, outcome, and predictors of success within 6 weeks of an opioid rotation among outpatients with cancer receiving strong opioids. Oncologist 2013;18:212-20.

12. Mercadante $S$, Bruera E. Opioid switching: a systematic and critical review. Cancer Treat Rev 2006;32:304-15.

13. Mercadante S, Caraceni A. Conversion ratios for opioid switching in the treatment of cancer pain: a systematic review. Palliat Med 2011;25:504-15.

14. Reddy A, Tayjasanant S, Haider A, et al. The opioid rotation ratio of strong opioids to transdermal fentanyl in cancer patients. Cancer 2016;122:149-56.

15. Reddy A, Yennurajalingam S, Desai H, et al. The opioid rotation ratio of hydrocodone to strong opioids in cancer patients. Oncologist 2014;19:1186-93.

16. Dale O, Moksnes K, Kaasa S. European Palliative Care Research Collaborative pain guidelines: opioid switching to improve analgesia or reduce side effects. A systematic review. Palliat Med 2011;25:494-503.

17. Reddy A, Yennurajalingam S, Reddy S, et al. The Opioid Rotation Ratio From Transdermal Fentanyl to "Strong" Opioids in Patients With Cancer Pain. J Pain Symptom Manage 2016;51:1040-5.

18. Bruera E, Kuehn N, Miller MJ, et al. The Edmonton Symptom Assessment System (ESAS): a simple method for the assessment of palliative care patients. J Palliat Care 1991;7:6-9.

19. Bruera E, MacMillan K, Hanson J, et al. Palliative care in a cancer center: results in 1984 versus 1987. J Pain Symptom Manage 1990;5:1-5.

20. Schuster M, Bayer O, Heid F, et al. Opioid Rotation in Cancer Pain Treatment. Dtsch Arztebl Int 2018;115:135-42. 
21. Reddy A, Schuler US, de la Cruz M, et al. Overall Survival among Cancer Patients Undergoing Opioid Rotation to Methadone Compared to Other Opioids. J Palliat Med 2017;20:656-61.

22. Thomsen AB, Becker N, Eriksen J. Opioid rotation in chronic non-malignant pain patients. A retrospective study. Acta Anaesthesiol Scand 1999;43:918-23.

23. Kim HJ, Kim YS, Park SH. Opioid rotation versus combination for cancer patients with chronic uncontrolled pain: a randomized study. BMC Palliat Care 2015;14:41.

24. Smith HS, Peppin JF. Toward a systematic approach to opioid rotation. J Pain Res 2014;7:589-608.

25. Argoff CE. Clinical implications of opioid pharmacogenetics. Clin J Pain 2010;26 Suppl 10:S16-20.

26. Muriel J, Margarit C, Barrachina J, et al. Pharmacogenetics and prediction of adverse events in prescription opioid use disorder patients. Basic Clin Pharmacol Toxicol 2019;124:439-48.

27. Pasternak GW. Incomplete cross tolerance and multiple mu opioid peptide receptors. Trends Pharmacol Sci 2001;22:67-70.

28. Pasternak GW, Childers SR, Pan YX. Emerging Insights into Mu Opioid Pharmacology. Handb Exp Pharmacol 2020;258:89-125.

29. Ross JR, Riley J, Quigley C, et al. Clinical pharmacology and pharmacotherapy of opioid switching in cancer patients. Oncologist 2006;11:765-73.

30. Kristensen K, Christensen CB, Christrup LL. The mu1, mu2, delta, kappa opioid receptor binding profiles of methadone stereoisomers and morphine. Life Sci 1995;56:PL45-50.

31. Tognoli E, Proto PL, Motta G, et al. Methadone for postoperative analgesia: contribution of N-methyl-Daspartate receptor antagonism: A randomised controlled trial. Eur J Anaesthesiol 2020;37:934-43.

32. Lugo RA, Satterfield KL, Kern SE. Pharmacokinetics of methadone. J Pain Palliat Care Pharmacother 2005;19:13-24.

33. Dean M. Opioids in renal failure and dialysis patients. J Pain Symptom Manage 2004;28:497-504.

34. Bruera E, Paice JA. Cancer pain management: safe and effective use of opioids. Am Soc Clin Oncol Educ Book 2015:e593-9.

35. Haumann J, Geurts JW, van Kuijk SM, et al. Methadone is superior to fentanyl in treating neuropathic pain in patients with head-and-neck cancer. Eur J Cancer 2016;65:121-9.

36. de Stoutz ND, Bruera E, Suarez-Almazor M. Opioid rotation for toxicity reduction in terminal cancer patients. J Pain Symptom Manage 1995;10:378-84.

37. Herndon CM, Jackson KC, 2nd, Hallin PA. Management of opioid-induced gastrointestinal effects in patients receiving palliative care. Pharmacotherapy 2002;22:240-50.

38. Qian Y, Haider A, Lu Z, et al. Factors Associated with Improvement in Uncontrolled Cancer Pain without Increasing the Opioid Daily Dose among Patients Seen by an Inpatient Palliative Care Team. J Palliat Med 2020;23:483-8.

39. Fine PG, Portenoy RK, Ad Hoc Expert Panel on Evidence R, et al. Establishing "best practices" for opioid rotation: conclusions of an expert panel. J Pain Symptom Manage 2009;38:418-25.

40. Zhao SZ, Chung F, Hanna DB, et al. Dose-response relationship between opioid use and adverse effects after ambulatory surgery. J Pain Symptom Manage 2004;28:35-46.

41. Moryl N, Santiago-Palma J, Kornick C, et al. Pitfalls of opioid rotation: substituting another opioid for methadone in patients with cancer pain. Pain 2002;96:325-8.

42. Walker PW, Palla S, Pei BL, et al. Switching from methadone to a different opioid: what is the equianalgesic dose ratio? J Palliat Med 2008;11:1103-8.

43. Tan C, Wong JF, Yee CM, et al. Methadone rotation for cancer pain: an observational study. BMJ Support Palliat Care 2020. doi: 10.1136/bmjspcare-2019-002175. [Epub ahead of print].

44. Benitez-Rosario MA, Salinas-Martin A, Aguirre-Jaime A, et al. Morphine-methadone opioid rotation in cancer patients: analysis of dose ratio predicting factors. J Pain Symptom Manage 2009;37:1061-8.

45. Lovell AG, Protus BM, Saphire ML, et al. Evaluation of QTc Interval Prolongation Among Patients With Cancer Using Enteral Methadone. Am J Hosp Palliat Care 2019;36:177-84.

46. Shah S, Diwan S. Methadone: does stigma play a role as a barrier to treatment of chronic pain? Pain Physician 2010;13:289-93.

Cite this article as: Legakis LP, Woo W, Cassel JB, Del Fabbro E. Comparison of opioid rotation on pain, symptoms, and daily opioid dose in a supportive care clinic. Ann Palliat Med 2021;10(6):6336-6343. doi: 10.21037/apm-21-325 